\title{
ラットの罰事態における非強化選択肢への反応生起
}

\author{
早稲田大学吉 野 俊彦 - 木 村裕
}

\author{
Response occurrence to the non-reinforced alternative through \\ punishment in rats
}

Toshihiko Yoshino and Hiroshi Kimura (Department of Psychology, School of Letters, Waseda University, Shinjuku-ku, Tokyo 162)

Each of eight rats was located in the experimental chamber mounted with two levers. Lever-pressing to either of the two was maintained by a schedule of food. After that, a punishment schedule of electric shocks was added. Neither the reinforcement nor the punishment schedule was programmed on the other lever, i.e. the non-reinforced alternative. The effect of reinforcement, and the joint effect of reinforcement and punishment on responses to the non-reinforced alternative were compared. During punishment sessions, responses to the non-reinforced alternative occurred significantly more often than during reinforcement sessions. The number of responses to the non-reinforced alternative was negatively correlated with that to the reinforced alternative during punishment sessions. Nevertheless, the occurrence of responses to the non-reinforced alternative was mainly observed during the first few sessions in punishment schedule, or after stepping up the intensity of electric shock. These results were discussed in relation to the two theories and models of punishment. The results imply that the two theories and models of punishment are necessary to explain the effect of punishment.

Key words: punishment, symmetrical law of effect, competing-response theory, matching, lever press, rats.

罰手続きは，罰する反応(以下所定の反応と呼ぶ)を抑 制させる以外に，様々な副次的な効果を持っと考えられ てきた。例えば，罰する個体に恐怖を与え，その恐怖が 弁別刺激に般化する，所定の反応以外の反応 (以下競合 反応と呼ぶ）を生起させるなどの効果である. 罰事態に 㧍ける競合反応が何を意味しているかについては，電撃 など無条件刺激による無条件反応，種に固有な防御反忘 (Bolles, 1970), 罰が逃避・回避条件づけの過程を含んで いるために強化・維持される受動回避反応 (Dinsmoor, 1954, 1977) など, 統一的な見解が得られていない.

従来, 行動を抑制させる罰の効果について, 大別して 2 つの説明がなされてきた. 対称的効果の法則と競合反 応理論である (Fantino \& Logan, 1979; Mackintosh, 1983; Rachlin \& Herrnstein, 1969). 対称的効果の法則 では，所定の反応が抑制されるのは罰の直接的な效果と 考えられ，競合反忘については説明しない。一方，競合 反応理論では，罰が競合反応を強化・維持することによ って間接的に所定の反応が抑制されると説明して，競合 反応の生起を予測する。しかし，何を競合反応とするか について統一的でないという問題は残されている.

Herrnstein $(1970,1974)$ は並立 (concurrent: 以下 conc.) VI, VI スケジュール下での選択行動を説明した 対応法則から，(1) 式を提唱したが，この式によって，
競合反応の問題の 1 つの解決法が示唆されている.

$$
B_{1}=\frac{k r_{1}}{r_{1}+r_{0}}
$$

$B_{1}$ は単一の選択肢における行動の指標 (反応率, または 反応従事時間)， $r_{1}$ は単一の選択肢に抒ける強化率， $r_{0}$ は選択肢以外加得る強化率, $k$ は反応率の漸近值。 Herrnstein (1974) によれば, 単一の反応が強化される事 態浪，反応することと反応しないこととの選択を含んで いる.これは，実験者が設定した反応をしないことに対 する強化率が想定できることを意味している，罰事態で は，(1) 式に扔いて，罰は選択肢の強化率 $\left(r_{1}\right)$ を減じる のでなく, それ以外の反応 (other behaviors) の強化率 $\left(r_{0}\right)$ を上げるように働くと考えられる. そして反応抑制 を， $r_{0}$ が大きくなり相対的に所定の反応率が小さくなる ためと説明する. この考えによれば，選択肢への反応を しないことが競合反応と位置づけられる。しかし，反応 をしないことの中に, 前述の種に固有な防御反応, 受動 回避反応や涷結反応などをも含むという曖昧さは残され る.

罰事熊の選択行動を説明しょうとした対応法則からの 以下の 2 つのモデルは, 前述の 2 つの罰の理論と密接に 関連している(例えば de Villiers, 1982; Deluty, 1982). ひとつは (2) 式の罰の減算モデル (Farley \& Fantino, 
1978; Farley, 1980; de Villiers, 1977, 1980, 1982) で ある. (2) 式は選択等態にお沙詨称的効果の法則の表 現式と考えられる (Deluty, 1976; Farley, 1980). ${ }^{1}$

$$
\log \frac{B_{1}}{B_{2}}=k \log \left(\frac{r_{1}-c p_{1}}{r_{2}-c p_{2}}\right)^{a}
$$

$B_{1}, B_{2}$ は 2 つの選択肢に対する行動の指標, $r_{1}, r_{2}$ はそ れぞれの選択肢で得られた強化率， $p_{1}, p_{2}$ はそれぞれの 選択肢で得られた罰率を示す， $k$ と $a$ は実験結果に基づ いて推定される定数, $c$ は罰刺激の強化刺激に対する比 率 (negative food unit: Farley \& Fantino, 1978; Davison \& McCarthy, 1988, p. 130) である. ${ }^{2}$

もらひとつは (3) の加算モデル (Deluty, 1976, 1982; Deluty \& Church, 1978) である. (3) 式は選択事態にお ける競合反応理論の表現式と考えられる (Deluty, 1976; Farley, 1980).

$$
\log \frac{B_{1}}{B_{2}}=k \log \left(\frac{r_{1}+c p_{2}}{r_{2}+c p_{1}}\right)^{a}
$$

2つのモデルについて比較検討した de Villiers (1980) と Farley (1980) の実験では，減算モデルが妥当である との結果が得られた. しかし, 彼らの検証には予測と記 述において不一致があり(吉野, 1986), 減算モデルでは 罰率が強化率より大きい場合に強化価が負となる問題点 がある (Davison \& McCarthy, 1988, p. 132).さらに, de Villiers (1982) と Deluty (1982) における議論でも, お互いのモデルの正当性を主張しあって結論に至ってい ない.

de Villiers (1980), Farley (1980) の検討では,この 2 つのモデルが異なる結果を子測するような笑験事態を設 定していた. そうした, 異なる結果が予測される事態の ひとつに，一方の選択肢の強化率と罰率が共にゼロであ る，つまり消去で少る事態が考えられる. ここで, 強化 事態から罰事態への移行により, 選択肢 1 への反店率が $50 \%$ に抑制されたとする ((2), (3) 式において $r_{1}=p_{1}>0$, $\left.r_{2}=p_{2}=0, c=0.5\right)$. (2) 式の相対值による表現式に基つ く, $B_{1}, B_{2}$ についての絶対反店率は，(4)，(5) 式のよう になる。

1 対応法則を表わすとき, Herrnstein $(1961,1970)$ に よる厳密な対応法則 (strict matching law) よりも, Baum (1974)による一般的対応法則 (generalized matching law) 起用いるのが，現在では一般的である. Allen (1981), Prelec (1984), Davison \& McCarthy (1988, p. 48)によれば, 嚴密な対応法則は一般的対応法則の特別 な場合である.ここでは罰のモデルについても一艘的詨 忘法則の形で表現した. (3) 式についても同様である.

2 c のかおりに， $\alpha$ が用いられることもある (de Villiers, 1980; Davison \& McCarthy, 1988, p. 130).

$$
\begin{aligned}
& B_{1}=k \frac{r_{1}-0.5 p_{1}}{r_{1}-0.5 p_{1}+r_{0}} \\
& B_{2}=k \frac{0}{r_{1}-0.5 p_{1}+r_{0}}
\end{aligned}
$$

$B_{1}$ は, $p_{1}=0$ のとき(強化事態)に比べると減少し, $B_{2}$ はゼ口，つまり反応は生じないと予測される.一方，(3) 式の相対值による表現式に基づくと， $B_{1}, B_{2}$ についての 絶対反応摔は，(6)，(7) 式のようになる.

$$
\begin{aligned}
& B_{1}=k \frac{r_{1}}{r_{1}+0.5 p_{1}+r_{0}} \\
& B_{2}=k \frac{0.5 p_{1}}{r_{1}+0.5 p_{1}+r_{0}}
\end{aligned}
$$

$B_{1}$ は，強化事態に比べると減少， $B_{2}$ は， $0.5 p_{1}$ が加わ ったことでゼロでなくなる，っまり反応が生じることが 予測される.

以上から，本実験では次の手続きによって罰の理論に

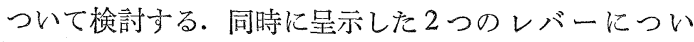
て，いずれか一方を強化スケジュールを設定したレバー (以下強化レバーとする)，他方を消去としたレバー（以 下非強化レバーとする) としてレバー押し反応を安定さ せる，その後，強化レバーのみに罰手続きを加え，電撃 の強度を様々に変化させる. このとき，非強化レバーへ の反応生起について，強化のみの事態と罰手続きを加え た事態とで比較検討する. 同時に，非強化レバーへの反 応生起が，罰の手続きによるものであるかを確認するた めに, 電撃強度の効果, 強化スケジュール, 罰スケジュ ールの効果についても検討する.

\section{突 験}

\section{方 法}

被験体 ウイスター系の雄のアルビノラット 8 匹を, 自由提食時の $85 \%$ に体重を統制した。体重統制の方法 は，実験セッション 30 分後に与えるペレットの量を調 節することによった。統制時の体重は 274.6-293.0 (平 均 282.92) g であった.

装 置 標準型のラット用スキナー箱 (Ralph Gerbrands 社製； $307 \times 248 \times 310 \mathrm{~mm}$ ：幅 $\times$ 奥行き $\times$ 高 さ）を用いた. 䬺皿が正面パネル下方中央，その左右 $65 \mathrm{~mm}$ に反応用レバー(約 $17 \mathrm{~g}$ の重さでマイクロスイ ッチを作動させた)が取り付けられていた。床には，直 径 $5 \mathrm{~mm}$ のステンレス製のグリッドが，その中心と中 心の間隔が $16 \mathrm{~mm}$ となるよら敷かれていた. スキナ 一箱は自作の木製防音箱 $(795 \times 520 \times 600 \mathrm{~mm})$ に入れ られ，換気と外部音のマスキングのために排気用ファン が回された. 1 回あたりの強化子は $45 \mathrm{mg}$ の固形ペレ ット (室町機械社製) 1 個であった. 電撃呈示装置は, 室 町機械社製の SGS 001 SHOCK GENERATOR / 
Table 1

Number of sessions, schedules, and changeover delay (COD) condition in the reinforcement and the punishment sessions

\begin{tabular}{|c|c|c|c|c|c|c|}
\hline \multirow{3}{*}{$\begin{array}{c}\begin{array}{c}\text { Rat } \\
\text { number }\end{array} \\
8703\end{array}$} & \multicolumn{2}{|c|}{ Number of sessions } & \multicolumn{4}{|c|}{ Schedules (COD : $2 \mathrm{~s}$ ) } \\
\hline & \multirow{2}{*}{$\begin{array}{c}\text { Reinforcement } \\
36\end{array}$} & \multirow{2}{*}{$\begin{array}{c}\text { Punishment } \\
119\end{array}$} & \multicolumn{2}{|c|}{ Reinforcement } & \multicolumn{2}{|c|}{ Punishment } \\
\hline & & & conc. ext & -VI30 s (Y) & conc. ext & $-\mathrm{VI} 30 \mathrm{~s}(\mathrm{Y})$ \\
\hline 8704 & 30 & 124 & conc. VR60 & $-\operatorname{ext} \quad(\mathrm{N})$ & conc. VR60 & $-\operatorname{ext}(\mathrm{N})$ \\
\hline 8705 & 57 & 120 & conc. VI30 & $s-e x t$ & conc. VI30 & s-ext \\
\hline 8706 & 46 & 138 & conc. VI30 & s-ext & conc. VR60 & -ext \\
\hline 8707 & 52 & 135 & conc. VR60 & -ext & conc. VI60 & s-ext \\
\hline 8708 & 61 & 129 & conc. VI30 & s-ext & conc. VI30 & $s-e x t$ \\
\hline 8709 & 39 & 122 & conc. ext & -VR60 (N) & conc. ext & $-V I 60 s(Y)$ \\
\hline 8710 & 59 & 121 & conc. ext & $-\mathrm{VI} 30 \mathrm{~s}(\mathrm{Y})$ & conc. ext & $-\mathrm{VR} 30(\mathrm{~N})$ \\
\hline
\end{tabular}

SCRAMBLER を用いた. 極性がスクランブルされた 電撃索前述のグリッドを通じて呈示した，電撃の呈示時 間は $100 \mathrm{~ms}$ であった. 以下に示す強度は，装置に付 属したメータによった，反応の晏定度を検討する為に累 積記録器 (Ralph Gerbrands 社製) を用いた. 罰手続 き中の音刺激の呈示のために, 三栄測器社製 PHONO STIMULATOR 3G13 を用いた. すべての実験手続き を通じて実験の制御とデータの収集にはマイクロコンピ ニータ (Rockwell 社製 AIM65) を用いた.

手続き 1) ハンドリング 1 日 5 分ずっで 5 日間行 なった。

2）実験箱へのアダプテーション 1 日 20 分ずつで 4 日間行なった．2）以下ではマスキング用ファンを回し た.

3) マガジントレーニング 1 日 60 強化のセッション を 2 日間行なった. 以上 2), 3) ではレバーは呈示しなか った.

4）シェイピング 漸次接近法により 1 日 60 強化で 2 日間行なった. 右もしくは左のレバーのいずれかを強化 レバーとして, そのレバーのみを呈示し，反応を形成し た.

5) 連続強化トレーニング 1 日 60 強化のセッション 安 2 日閒行なった. ここでも強化レバーのみを呈示し t.

6) 予備訓練 6) 以下では, 強化レバーと非強化レバ 一の両方を呈示した. すべてのラットについて，強化レ バーに対する強化スケジュールを, VI $5 \mathrm{~s}$, VI $10 \mathrm{~s}$, VI $15 \mathrm{~s}$, VI $20 \mathrm{~s}$ の順に移行させた。強化スケジュールの 移行は, セッション中に長い反応休止が観察されない等, 比較的安定した反応率によって直線的な累積記録が得ら れたと実験者が判断することによった。 ラット 8704， 8707,8709 の 3 個体については, その後, VR 30, VR
45, VR 60 と移行させた.ここでは，1セッションあた りの強化数が 60 を越え, かつ, 累積記録において長い反 応休止が観察されなかった際に，強化スケジュールを移 行した. これは，VI スケジュールとVR スケジュール とで 1 セッションあたりの強化数に差が生じないように するためであった. VI スケジュールについては, 通常 の並立スケジュール事態と同様に，2s の切り替え反応 遅延手続き (changeover delay : 以下 COD) を設けた.

7）強化セッション Table 1 に強化セッションと次 項に述べる罰セッションにおける各ラットの手続きを示 した. 強化セッションでは, VI $30 \mathrm{~s}$ または VR 60 の いずれかの強化スケジュールによって，ラット毎に，連 続 5 セッションで以下に示す安定基準 1-3 を満たすま でレバー押し訓練を行なった. 3 つの安定基準を満たし た最後の連続 5 セッションを強化ベースラインとした. この強化ベースラインでのデータを, 罰セッションでの 反応率がどの程度抑制されたかを検討するための基準と した.

安定基準 1: 連続 5 セッションで，反応配分（相対反 応率) の変動 (相対反応率の最大值と最小值の差) がその 平均值の $\pm 2.5 \%$ 以内で女ること.

安定基準 2: 連続 5 セッションで, 合計反応数の標準 偏茥が平均値の $3.0 \%$ 以内であること.

安定基準 3: 連続 5 セッションで絶対反応率，相対反 応率のいずれもが一次的な増加・減少傾问にないこと. この安定基準を満たすのに 30-61(平均 47.25) セッショ ンを要した。

8）罰セッション ラット毎に，罰セッションにおけ る反応率を強化ベースラインの $50 \%$ とした場合に，1セ ッションあたりの強化数と罰数とがほぼ等しくなるよう に罚スケジュールを設定した。これは, (2),(3)式の定数 $c$ をラット間で共通にするためであった。ここでも，VI 
スケジュールの手続きには $2 \mathrm{~s}$ のCOD を設定した. 電 撃の強度は $2.0 \mathrm{~mA}$ より始め, ラット毎に強化ベース ラインの $50 \%$ の反応率になるまで $0.5 \mathrm{~mA}$ ステップ で調節した。 その後は特に基準を設けず, $0.1 \mathrm{~mA}$ ステ ップで抑制と回復を繰り返すように，馴化を考慮しなが ら変化させた. 強度は最大 $6.0 \mathrm{~mA}$, 最小 $0.0 \mathrm{~mA}$ であ った. 罰手続きが強化スケジュールの弁別刺激とならな いように (Azrin \& Holz, 1966), 罰セッション中は $1000 \mathrm{~Hz}$ の純音 $(80 \mathrm{~dB})$ を呈示した.

強化セッションより以降の条件では 1 セッションは 30 分とし, 1 日 1 セッションを行なった. VI, VR の数 列は Flesher \& Hoffman (1962) によった.

\section{結果}

強化レバーへの反応について，全罰セッションにおけ る電撃強度と強化レバーへの反応率との相関をラット毎 に, Table 2 に示した.これによれば, 電撃強度と 1 セ ッションあたりの強化レバーの反応数とは必ずしも負の 相関を示して扔らず, 強化レバーへの反応が電撃の強度 に直接対応して抑制されていなかったことがわかる.す べてのラットについて, 強化レバーへの反念が抑制され るのに伴って，予備訓練や強化セッションで観察された よりも多くの反応が非強化レバーに生起する傾向が示さ れた. 強化セッションと罰セッションの各々について， 1 セッションあたりの非強化レバーへの反応数を Table 3 にまとめた. 8 匹中 5 匹が，罰セッションで有意によ り多くの反応をしたことがわかる。しかし，罰セッショ ン中に括いても非強化レバーへの反応は必ずしも持続的 でなかった. 罰セッション初期や電撃強度が上げられた
Table 2

Pearson's product-moment correlation coefficients for the intensity of electric shock and the number of responses on the reinforced lever

\begin{tabular}{cc}
\hline $\begin{array}{c}\text { Rat } \\
\text { number }\end{array}$ & $\begin{array}{c}\text { Correlation } \\
\text { coefficient }\end{array}$ \\
\hline 8703 & $.244^{* *}$ \\
8704 & $.354^{* * *}$ \\
8705 & -.074 \\
8706 & $-.232^{* *}$ \\
8707 & $-.171^{*}$ \\
8708 & $-.280^{* *}$ \\
8709 & $.454^{* * *}$ \\
8710 & -.002
\end{tabular}

Notes: the level of significance by no correlated $t$-test.

$* p<.05, * * p<.01, * * * p<.001$.

直後のセッションで, 強化レバーへの反応が抑制された 場合に特徴的に非強化レバー一反応が生じる傾向が観察 された. 強化レバーへの反応数の, 直前のセッションに おける強化レバーへの反応数に対する比率を算出した ${ }^{3}$.

$3 \quad r=\mathrm{NUM}_{i} / \mathrm{NUM}_{i-1}$

$\mathrm{NUM}_{i}$ は $i$ セッション目の強化レバーへの反応数, $r$ は 直前のセッションに対する抑制率を表す， $r$ は直前のセ ッションに比べて, 反応が促進したとき 1 より大きく, 抑制されたとき 1 よりささなる。 また，直前のセッシ ヨンに比べて反応の抑制が大きいほど值は小さくなる.

Table 3

Mean number of responses per session on the reinforced and the non-reinforced lever and the results of $t$-test for the two sessions under the two different conditions

\begin{tabular}{cccccc}
\hline \multirow{2}{*}{$\begin{array}{c}\text { Rat } \\
\text { number }\end{array}$} & \multicolumn{2}{c}{$\begin{array}{c}\text { Mean number of responses on } \\
\text { the reinforced lever }\end{array}$} & & \multicolumn{2}{c}{$\begin{array}{c}\text { Mean number of responses on } \\
\text { the non-reinforced lever }\end{array}$} \\
\cline { 2 - 3 } \cline { 5 - 6 } $\begin{array}{c}\text { Reinforcement } \\
\text { sessions }\end{array}$ & $\begin{array}{c}\text { Punishment } \\
\text { sessions }\end{array}$ & & $\begin{array}{c}\text { Reinforcement } \\
\text { sessions }\end{array}$ & $\begin{array}{c}\text { Punishment } \\
\text { sessions }\end{array}$ \\
\hline 8703 & $2188.31^{* * *}$ & 1689.81 & & 0.29 & $3.59^{* * *}$ \\
8704 & $3887.83^{* * *}$ & 2375.78 & & 5.03 & $11.07^{* * *}$ \\
8705 & $2376.07^{* * *}$ & 1345.01 & & 3.27 & 3.91 \\
8706 & $2472.49^{* * *}$ & 1489.71 & & $8.20^{* * *}$ & 3.84 \\
8707 & $4194.85^{* * *}$ & 2304.74 & & 6.02 & $9.12^{* * *}$ \\
8708 & $2988.20^{* * *}$ & 1522.23 & & 4.33 & $6.53^{* * *}$ \\
8709 & $3110.82^{* * *}$ & 1639.61 & & 0.95 & 1.09 \\
8710 & $3446.97^{* * *}$ & 1583.09 & & 1.00 &
\end{tabular}

Notes: the level of significance by $t$-tesc.

$* p<.05, * * * p<.001$. 
Table 4

Pearson's product-moment correlation coefficients for the number of responses on the nonreinforced lever and the ratio of suppression in the punishment sessions

\begin{tabular}{cc}
\hline Rat number & Ratio of suppression \\
\hline 8703 & $-.394 * * *$ \\
8704 & -.169 \\
8705 & -.149 \\
8706 & $-.429 * * *$ \\
8707 & $-.303^{* * *}$ \\
8708 & $-.469 * * *$ \\
8709 & -.087 \\
8710 & -.159
\end{tabular}

Notes: the level of significance by no correlated $t$-test.

$* * * p<.001$.

この比率と非強化レバーへの反応数との相関を Table 4 に示した. 相関はすべてのラットについて負の值を示し ており，8個体中 4 個体では有意であった。

次に, 非強化レバーへの反応数と, 強化レバーへの反 応数, 電撃強度の間の相関係数を Table 5 にまとめた。 これによると, 罰セッションでは強化レバーと非強化レ バーへの反応数は，すべてのラットにおいて負の相関を 示した. 無相関検定の結果, この負の相関はいずれも有 意であった。一方, 強化セッションにおいて有意な負の 相関が得られたのは 8710 の 1 個体であった. 電撃強度 との相関では, 8706, 8707, 8708 の3 個体に有意な正の 相関が見られたが，8709 では有意な負の相関が見られ た.

Table 6 に，強化セッションと罰セッションのそれぞ れについて, 非強化レバーへの反応数と強化数との相関 係数をまとめた. これについては, 次項で考察する.

以上から，1） 8 匹中 5 匹について, 強化セッションに 比ベて罰セッションでより多くの反応が非強化レバーで 生起したこと，2) 非強化レバーへの反応数は, 罰セッシ ヨンでのみ強化レバーへの反応数と有意な負の相関を示 したこと，3) 非強化レバーへの反応数は電撃強度の効果 と必ずしも関連していなかったことがわかった.これら の結果は, 強化, 罰のスケジュールが VI, VR のいず れであるかに関係なかった。 また，左右いずれのレバー が強化レバーであっても, 結果に差はみられなかった.

\section{考察}

8 匹中 5 匹において，強化セッションより罰セッショ
Table 5

Pearson's product-moment correlation coefficients for the number of responses to the non-reinforced lever and to the reinforced lever in the reinforcement and in the punishment sessions, and the intensity of electric shock

\begin{tabular}{ccccc}
\hline \multirow{2}{*}{$\begin{array}{c}\text { Rat } \\
\text { number }\end{array}$} & $\begin{array}{c}\text { Reinforcement } \\
\text { sessions }\end{array}$ & & \multicolumn{2}{c}{$\begin{array}{c}\text { Punishment } \\
\text { sessions }\end{array}$} \\
\cline { 5 - 5 } \cline { 5 - 5 } & $\begin{array}{c}\text { Reinforced } \\
\text { lever }\end{array}$ & & $\begin{array}{c}\text { Reinforced } \\
\text { lever }\end{array}$ & $\begin{array}{c}\text { Intensity of } \\
\text { electric shock }\end{array}$ \\
\hline 8703 & -.216 & & $-.642^{* * *}$ & -.095 \\
8704 & .133 & & $-.562^{* * *}$ & -.124 \\
8705 & -.198 & & $-.317^{* * *}$ & .137 \\
8706 & -.208 & & $-.393^{* * *}$ & $.216^{*}$ \\
8707 & .092 & & $-.488^{* * *}$ & $.430^{* * *}$ \\
8708 & -.076 & & $-.688^{* * *}$ & $.227 * *$ \\
8709 & .029 & & $-.467 * * *$ & $-.275^{* *}$ \\
8710 & $-.526 * * *$ & $-.412^{* * *}$ & -.063
\end{tabular}

Notes: the level of significance by no correlated $t$-test.

$$
* p<.05, * * p<.01, * * * p<.001 \text {. }
$$

Table 6

Pearson's product-moment correlation coefficients and the results of $t$-test for the number of responses on the non-reinforced lever and the number of reinforcements in the reinforcement and in the punishment sesions, and the number of punishment in the punishment sessions

\begin{tabular}{|c|c|c|c|}
\hline \multirow{2}{*}{$\begin{array}{c}\text { Rat } \\
\text { number }\end{array}$} & \multicolumn{2}{|c|}{$\begin{array}{c}\text { Number of } \\
\text { Reinforcements }\end{array}$} & $\begin{array}{l}\text { Number of } \\
\text { Punishments }\end{array}$ \\
\hline & $\begin{array}{l}\text { Reinforcement } \\
\text { sessions }\end{array}$ & $\begin{array}{l}\text { Punishment } \\
\text { sessions }\end{array}$ & $\begin{array}{l}\text { Punishment } \\
\text { sessions }\end{array}$ \\
\hline 8703 & $-.411^{*}$ & $-.650 * * *$ & $-.624 * * *$ \\
\hline 8704 & .121 & $-.566 * * *$ & $-.562 * * *$ \\
\hline 8705 & $-.303^{*}$ & $-.541 * * *$ & $-.539 * * *$ \\
\hline 8706 & $-.561 * * *$ & $-.675 * * *$ & $-.331 * * *$ \\
\hline 8707 & $-.310 *$ & $-.481 * * *$ & $-.486 * * *$ \\
\hline 8708 & -.220 & $-.790 * * *$ & $-.782^{* * *}$ \\
\hline 8709 & -.035 & $-.466 * * *$ & $-.457 * * *$ \\
\hline 8710 & -.021 & $-.374 * * *$ & $-.412 * * *$ \\
\hline
\end{tabular}

Notes: the level of significance by no correlated $t$-test.

$* p<.05, * * * p<.001$. 
ンでの方が非強化レバーに対して多くの反応が生じたこ とについては, 罰の効果と考える以外にも次の 2 つの可 能性が考光られる.まず, “レバー押し”が般化したこ とによる可能性である. 次に，罰手続きによって強化レ バーへの反応数が低下し，そのために強化数も低下した ことによる, 強化数の効果の可能性が考光られる.

まず前者関しては，2つのレバーが呈示されていた 点で強化セッションでも罰セッションでも同一であっ た.しかし, 強化セッションでは強化を随伴する反応が 般化し, 罰セッションでは強化と罰の両方が随伴する反 応が般化していたと考えられる.したがって, 非強化レ バーへの反応は, 強化セッションのほうが罰セッション よりむ多くなると考えられる.しかし，非強化レバーへ の反応は, 強化セッションより罰セッションにおいて高 い頻度で生じていた (Table 3)。また, 強化レバーへの 反応数と非強化レバーへの反応数の相関は, 罰セッショ ンでのみ有意となる傾向にあった (Table 4)。これらの 事実は, 非強化レバーへの反応生起のパターンが，強化 セッションと罰セッションとで異なっていたことを示し て预り, 般化の可能性は否定される.

強化数の効果は, Brethower \& Reynolds (1962)の, 無罰コンポーネントでの行動詨比によって競合反応理論 との関連性を検討した実験において指摘され，否定され ていた. 強化数の効果によって非強化レバーに反応が生 ビたのなら，強化セッションと罰セッションを通じて， 強化数と非強化レバーへの反応数との関係は一定である と考えられる．罰セッションではすべてのラットについ て有意な負の相関が示され，強化セッションでは 8 個体 中 4 個体に負の相関が示されて叔り (Table 6), 必ずし も一定とはいえない。亦た，罰セッションにおいて，罰 数と非強化レバーへの反応数との相関は, すべてのラッ トについて有意な負の值であった。こうした結果につい ては，次のように考えられる. 強化も罰も強化レバーー の反応に随伴して抒り, 強化レバーへの反応数と強化 数, 罰数とは高い相関となる. 一方で, 非強化レバーへ の反応数は, 罰事態では強化レバーへの反応数と高い負 の相関があり，結果的に非強化レバーへの反応数と罰 数, 強化数との相関も高い負の值を示していたと考兄ら れる。

以上から，この実験に打いて非強化レバーへの反応が 生じたのは罰手続きの効果であったと考えられる。競合 反応理論は, 罰セッションで非強化レバーへの反応が生 じた事実に対応し, 所定の反応以外の反応が生起するこ とによって所定の反応が抑制されるという考えが，2つ のレバーーの反応数間の高い負の相関性に対応してい る. 一方, 対称的効果の法則では, 罰セッションに抢け る非強化レバーへの反応について説明されない。

以上から $2 つ の$ 罰の理論について結論するには, 次の
ような問題点が残されている. 非強化レバーへの反応 は，強化レバーへの反応が抑制されていたときにも，必 ずしも安定していなかった. 例えば, 強化レバーへの反 応が完全に抑制されていても, 非強化レバーへの反応が 生じなかった場合もあった。この事実は, 競合反応の生 起によって所定の反応が抑制されるという考えでは説明 できない. したがって, 競合反応理論, 対称的効果の法 則のいずれか一方だけでは, 今回の実験結果を説明でき ないことになる。

対応法則からの 2 つのモデルもいずれか一方では不十 分である. (5) 式(対称的效果の法則の表現式)によれば, 非強化レバーへの反応は生じないと予測される。しか し, 罰セッションで, 強化セッションに比べて有意に多 くの反応が生じる傾向がみられた。一方，(7) 式(競合反 応理論の表現式）によれば, 罰セッションで非強化レバ 一への反応が生じ, 罰手続きが設定されていれば持続す ると予測される. 非強化レバーへの反応は生じたが, 強 化レバーへの反応数の $1 \%$ にも満たない程度であり (Table 3), 必ずしも持続的でなかった.こうした事実は, いずれか一方のモデルを妥当とした報告 (de Villiers, 1980; Farley, 1980) や主張 (de Villiers, 1982; Deluty, 1982）を支持しない.

ところで, Table 4 に示したように非強化レバーへの 反応は, 罰セッション初期や電摮強度が上げられた直後 のセッションで特徴的に生じる傾向があった. これは, 罰の $2 つ の$ 理論について段階的な理解の可能性を示唆す る. 罰が導大された初期に扔いて特徵的に非強化レバー に反応が生起したことは競合反応理論, その後の抑制が 安定した段階に扔いては対称的効果の法則が，それぞれ あてはまるということである. Fantino \& Logan (1979) も指摘するように, 通常, 競合反応は特定できない.今 回の非強化レバーへの反応も, 競合反応と仮定できるう ちのひとつである. 全体的な活動水準の増加や, 所定の 反応が完全に抑制された場合の凍結反応も競合反応のカ テゴリーに含めても䛊りとはいえない，この競合反応の 特定の問題は, 今後の重要な課題として残される. しか し，従来の択一的な捉え方では説明できない今回の害験 事実を，前述の段階的な捉え方でうまく説明できるので ある.

今後, この非強化レバーでの反応生起が，罰手続きに のみ観察される特有の現象であるかを検討する必要があ る. 今回の実験では, 強化レバーについて強化と罰が設 定されて㜿り, 典型的な接近一回避のコンフリクト事態 であった. 強化セッションから両方のレバーを消去手続 きにした場合にどうなるか，また，強化については両方 のレバーに消去手続きを用い，強化されていたレバーに のみ罰手続きを設定するとどうなるかといった実験的検 討が必要であると考えられる. 


\section{引用文献}

Allen, C. M. 1981 On the exponent in the "generalized" matching equation. Journal of the Experimental Analysis of Behavior, 35, 125-127.

Azrin, N.H., \& Holz, W. C. 1966 Punishment. In W. K. Honig (Ed.), Operant behavior: Areas of research and application. New York: Appleton-Century-Crofts. Pp. 380-447.

Baum, W. M. 1974 On two types of deviation from the matching law: Bias and undermatching. Journal of the Experimental Analysis of Behavior, 22, $231-242$

Bolles, R. C. $1970 \quad$ Species-specific defense reactions and avoidance learning. Psychological Revierv, 77, $32-48$.

Brethower, D. M., \& Reynolds, G. S. 1962 A facilitative effect of punishment on unpunished behavior. Journal of the Experimental Analysis of Behavior, 5, 191-199.

Davison, M., \& McCarthy, D. 1988 The matching law. Hillsdale, N. J. : Erlbaum.

Deluty, M. Z. 1976 Choice and the rate of punishment in concurrent schedules. Journal of the Experimental Analysis of Behavior, 25, 75-80.

Deluty, M. Z. 1982 Maximizing, minimizing, and matching between reinforcing and punishment situations. In M. L. Commons, R. J. Herrnstein \& H. Rachlin (Eds.), Quantitative analysis of accounts. Vol. II. Cambridge, M.A. : Ballinger. Pp. 305-325.

Deulty, M. Z., \& Church, R. M. 1978 Time-allocation matching between punishing situations. Journal of the Experimental Analysis of Behavior, 29, 191198.

de Villiers, P.A. 1977 Choice in concurrent schedules and a quantitative formulation of the law of effect. In W. K. Honig \& J.E.R. Staddon (Eds.), Handbook of operant behavior. Englewood Cliffs, N. J. : Prentice-Hall. Pp. 233-287.

de Villiers, P. A. 1980 Toward a quantitative theory of punishment. Journal of the Experimental Analysis of Behavior, 33, 15-25.

de Villiers, P.A. 1982 Toward a quantitative theory of punishment. In M. L. Commons, R. J. Herrnstein \& H. Rachlin (Eds.), Quantitative analysis of accounts. Vol. II. Cambridge, M. A. : Ballinger. Pp. $327-344$
Dinsmoor, J. A. 1954 Punishment I: The avoidance hypothesis. Psychological Review, 61, 34-46.

Dinsmoor, J.A. 1977 Escape, avoidance, punishment: Where do we stand? Journal of the Experimental Analysis of Behavior, 28, 83-85.

Fantino, E., \& Logan, F.A. 1979 The experimental analysis of behavior: A biological perspective. San Francisco: W. H. Freeman.

Farley, J. 1980 Reinforcement and punishment effects in concurrent schedules: A test of two models. Journal of the Experimental Analysis of Behavior, 33, 311-326́.

Farley, J., \& Fantino, E. 1978 The symmetrical law of effect and the matching relation in choice behavior. Journal of the Experimental Analysis of Behavior, 29, 37-60.

Flesher, M., \& Hoffman, H.S. 1962 A progression for generating variable-interval schedules. Journal of the Experimental Analysis of Behavior, 5, 529-530.

Herrnstein, R. J. 1961 Relative and absolute strength of response as a function of frequency of reinforcement. Journal of the Experimental Analysis of Behavior, 4, 267-272.

Henrrstein, R.J. 1970 On the law of effect. Journal of the Experimental Analysis of Behavior, 13, 243-266.

Herrnstein, R. J. 1974 Formal properties of the matching law. Journal of the Experimental Analysis of Behavior, 21, 159-164.

Mackintosh, N.J. 1983 Appetitive and aversive reinforcement. In N.J. Mackintosh (Ed.), Conditioning and associative learning. New York: Oxford University Press. Pp. 112-141.

Prelec, D. 1984 The assumptions underlying the generalized matching law. Journal of the Experimental Analysis of Behavior, 41, 101-107.

Rachlin, H., \& Herrnstein, R. J. 1969 Hedonism revisited: On the negative law of effect. In B. A. Campbell \& R. M. Church (Eds.), Punishment and aversive behavior. New York: Appleton-CenturyCrofts. Pp. 83-109.

吉野俊彦 1986 ラットの罰事態における選択行動 早 稲田大学大学院文学研究科紀要，32，238-241.

-1988. 12. 26. 受稿, 1990.9.8. 受理—— 